\title{
DA FALA PARA A LEITURA: ANÁLISE VARIACIONISTA
}

\author{
Dermeval da HORA* \\ Maria de Fátima S. AQUINO**
}

- RESUMO: Os estudos variacionistas no Brasil têm focalizado, em sua maioria, os níveis linguísticos fonológico e sintático. Os vários projetos que se pautam em dados coletados em diferentes comunidades (VARSUL, PEUL etc.) procuram abordar seus resultados, utilizando todo o aparato teórico-metodológico que a Sociolinguística Variacionista tem colocado à disposição. Com base em resultados obtidos ao longo da implementação do Projeto Variação Linguística no Estado da Paraíba - VALPB (HORA, 1993), que tem seu corpus estratificado segundo o sexo, a faixa etária e os anos de escolarização, e buscando lançar um olhar para um novo conjunto de dados, dessa vez voltados para a leitura, este artigo contempla a variação linguística na leitura oral de alunos da primeira fase do ensino fundamental, tendo como processos de análise: ditongação, monotongação e apagamento do "d" no grupo -ndo. Os dados analisados apontam uma forte influência da variante dialetal do aluno na leitura oral. É essa relação entre o que o aluno fala e o que o aluno lê que motiva a busca por propostas de análise que vão além daquilo que a escola preconiza.

- PALAVRAS-CHAVE: Sociolinguística. Variação. Leitura e ensino.

\section{Introdução}

Em 1993, foi iniciado o Projeto Variação Linguística no Estado da Paraíba - VALPB, apoiado pelo CNPq, tendo como principal objetivo traçar o perfil linguístico do falante paraibano, considerando os aspectos fonológicos, gramaticais e textuais. A estratificação social do projeto contemplou as seguintes restrições: sexo, anos de escolarização e faixa etária. Ao todo, foram entrevistados 60 informantes, por cerca de 45 a 60 minutos de gravação com cada um deles.

Os dados, depois de transcritos e armazenados eletronicamente e também editados sob forma impressa, serviram de base para análises as mais variadas possíveis. Foram inúmeros os trabalhos que neles se pautaram. Teses, dissertações, artigos, apresentações em eventos, todas essas modalidades se valeram do corpus para promover discussões e contribuir para que se

\footnotetext{
* UFPB - Universidade Federal da Paraíba. João Pessoa - Paraíba - Brasil. 58059-970 - ho_ra@hotmail.com

** UFPB - Universidade Federal da Paraíba. João Pessoa - Paraíba - Brasil. 58059-970 - fatimaaquinouepb@yahoo. com.br
} 
compreenda como dados de uma comunidade específica podem auxiliar na compreensão da teoria linguística como um todo.

Com o avanço dos estudos sociolinguísticos, novas perspectivas de aplicação desses estudos foram surgindo, em alguns casos de forma interdisciplinar com outras correntes teóricas da linguística contemporânea. Desta forma, os estudos que, inicialmente, eram de caráter apenas descritivo, isto é, tinham como objetivo descrever o perfil da comunidade de fala, passaram a ter uma nova aplicação teórica ou prática, para atender às novas demandas das pesquisas científicas advindas dos novos conhecimentos adquiridos com as "descobertas" sociolinguísticas.

Neste artigo, serão analisados três processos de formas variantes na oralização do texto escrito e sua interferência no processo de leitura. Todos os três trabalhos resultaram de pesquisa com dados do VALPB, tendo como produto final a dissertação de suas autoras. A análise toma por base processos da fala espontânea que foram estudados por Aquino (2004), Silva (2004) e Martins (2004). Aquino (2004), pesquisando sobre o processo de ditongação em formas como "fa[j]s, "tre[j]s", constata que os falantes menos escolarizados são os que mais aplicam a regra. No estudo de Silva (2004), a escolaridade exerce forte influência no processo de monotongação, como em "f[e]ra" para "feira", "[o]tro" para "outro". A autora constata que quanto mais alto o nível de escolaridade menor é o uso da forma monotongada. Martins (2004), observando o comportamento da variável anos de escolarização, constata que o apagamento da oclusiva 'd' no grupo -ndo, como em "falano", está em uma relação inversamente proporcional ao nível de escolaridade, isto é, à medida que aumenta o nível de escolaridade, diminui o uso da regra do apagamento.

Para dar conta da proposta, assim está estruturado o artigo: na seção 1, será apresentada uma visão sobre a leitura no cenário da variação linguística; na seção 2 , será apresentada a metodologia utilizada; na seção 3, uma visão geral dos fenômenos controlados durante a leitura e, em seguida, uma análise de cada um deles.

\section{A leitura no cenário da variação linguística}

As primeiras contribuições do estudo da variação para a educação foram trazidas pelas pesquisas de Labov sobre o inglês dos negros nos Estados Unidos. Os resultados de suas pesquisas refutaram a visão corrente, à época, de que as crianças falantes dessa variedade do inglês apresentavam deficiências de habilidades linguísticas. Tais estudos contribuíram para a valorização dos dialetos falados pelos grupos minoritários.

No campo da leitura, ressalta-se a importante contribuição das pesquisas de Labov e Baker $(2001,2003)$. Os autores analisam o processo de leitura oral de 
crianças das classes minoritárias (afro-americanos, latinos e brancos) e mostram como a língua da comunidade dessas crianças influencia a leitura oral. Os autores diferenciam os erros de leitura (decodificação errada da palavra) dos supostos erros decorrentes da influência do dialeto do aluno. Eles defendem que os perfis de erro de leitura de grupos étnicos são, de certo modo, previsíveis da estrutura de suas línguas maternas e que métodos de leitura que levam em conta as diferenças étnicas, sociais e econômicas, terão êxito, reduzindo a diferença no aprendizado de leitura.

No Brasil, destacam-se as pesquisas de Bortoni-Ricardo (2004) em que enfatiza o monitoramento da fala para a análise do português brasileiro no ambiente escolar e em outros ambientes sociais. Bortoni-Ricardo (2005) denomina de Sociolinguística Educacional todas as propostas e pesquisas que tenham por objetivo contribuir para o aperfeiçoamento do processo educacional.

Destacam-se, também, as importantes contribuições das pesquisas de Mollica (1998, 2003) com análise de formas variantes da fala e sua possível influência na escrita de alunos da educação básica.

Neste artigo, será investigada a influência de formas variantes da fala na leitura de alunos da primeira fase do ensino fundamental.

\section{A variação em pauta: metodologia}

Os dados aqui apresentados são de uma pesquisa realizada em uma escola pública no município de Guarabira-PB. O corpus da pesquisa é composto por leitura de um texto realizada por 30 (trinta) alunos do $3^{\circ}$ ao $5^{\circ}$ ano do ensino fundamental pertencentes à classe socioeconômica baixa e idade variando entre 08 e 11 anos. Crianças em idade escolar compatível, em média, com o ano cursado. Aos alunos, foi apresentado um texto e solicitada a leitura individual em voz alta; antes de proceder à leitura para gravação, o aluno tinha um primeiro contato com o texto. Assim que ele sinalizasse que estava pronto, tinha início a gravação da leitura em voz alta.

Como o procedimento metodológico guiou-se por uma concepção sociolinguística, mesmo estando em uma situação de linguagem que exigia certo monitoramento da fala, os alunos foram estimulados a fazerem uma leitura o mais natural possível.

A leitura gravada foi transcrita ortograficamente e, em seguida, foi feita a codificação e quantificação dos dados para a análise. Foram estabelecidos, previamente, alguns fenômenos variáveis para serem analisados: monotongação, ditongação, apagamento do 'd' no grupo -ndo, apagamento do rótico, rotacismo, simplificação do grupo consonantal etc. Apenas os três primeiros serão aqui 
analisados. Em seguida, os dados codificados e quantificados foram submetidos ao tratamento estatístico por meio do pacote de programa estatístico $\mathrm{R}$ ( $\mathrm{R}$ DEVELOPMENT CORE TEAM, 2007), para que pudesse ser obtida a frequência de ocorrência de cada forma variante em cada ano pesquisado.

Em uma análise inicial da leitura dos alunos, considerou-se que todos se comportaram de forma espontânea na realização do evento de leitura. No início, alguns demonstraram certo desconforto para com o momento, mas logo em seguida, ao término do primeiro parágrafo, por exemplo, já se comportavam de forma mais espontânea, sem prestar muita atenção à sua linguagem. A atenção, nesse momento, já estava mais voltada para o conteúdo do texto. O envolvimento com o conteúdo assegura a continuidade do fluxo de fala (LABOV, 2008).

\section{Análise dos dados: ditongação, monotongação e apagamento do 'd' no grupo -ndo}

Na quantificação dos fenômenos variáveis, foi observado que, em todos os anos pesquisados, ocorreram todos os tipos de fenômenos estabelecidos previamente, muitos dos quais não serão aqui tratados. Os resultados quantitativos apresentados nos revelaram aspectos interessantes dos fenômenos variáveis pesquisados. Na tabela 1 tem-se a porcentagem de ocorrência de cada forma variante por ano de escolaridade.

\section{Tabela 1 - Porcentagem de ocorrência de formas variantes por ano de escolaridade}

Fenômeno variável

Ano de escolaridade

\begin{tabular}{cccc} 
& $\mathbf{3}^{\mathbf{0}}$ & $\mathbf{4}^{\mathbf{0}}$ & $\mathbf{5}^{\mathbf{0}}$ \\
\hline Ditongação & $28,89 \%$ & $32,63 \%$ & $34,21 \%$ \\
\hline Monotongação & $23,08 \%$ & $31,54 \%$ & $68,46 \%$ \\
\hline Apagamento $/ \mathbf{d} /$-ndo & $3,33 \%$ & $8,89 \%$ & $2,22 \%$ \\
\hline
\end{tabular}

Fonte: Elaboração própria.

Ao serem comparadas as formas variantes controladas, percebe-se que o percentual de ocorrência mais alto está relacionado à monotongação e no quinto ano. O processo de ditongação tem comportamento muito próximo para os três anos, e é o apagamento do 'd' no grupo -ndo que tem percentuais mais baixos.

Comparando a porcentagem de ocorrência de alguns fenômenos entre os anos de escolaridade, percebe-se que o $3^{\circ}$ ano é o que apresenta menor porcentagem de 
ocorrência nos seguintes fenômenos: Ditongação - $3^{\circ}$ ano (28,89\%), $4^{\circ}$ ano (32,63\%) e $5^{\circ}$ ano (34,21\%); Monotongação - $3^{\circ}(23,08 \%)$, $4^{\circ}$ ano (31,54\%) e $5^{\circ}$ ano $(68,46 \%)$.

Esses valores apresentados para os ditongos e monotongos vão de encontro às asserções apresentadas por Aquino (2004) e Silva (2004) sobre a relação entre nível de escolaridade e o uso da forma com ditongação e monotongação, respectivamente, com análise de língua falada. Em seus estudos, as autoras constataram que quanto maior o nível de escolaridade menor o uso da forma monotongada e da forma com ditongo. Então, por que na leitura oral ocorre o processo inverso e o menor ano de escolaridade é o que apresenta a menor frequência de uso?

Relacionando os resultados quantitativos às observações do comportamento de leitura dos alunos, infere-se que a explicação para a menor ocorrência nos alunos de $3^{\circ}$ ano reside no fato de grande parte deles, por ainda não terem um domínio eficiente de leitura, fazer uma leitura silabada, em que é feita a decodificação da palavra por meio da relação letra/som. Nesse processo, o aluno pronuncia exatamente todos os fonemas que compõem a palavra, o que inibe o apagamento ou acréscimo de algum elemento.

Comparando, ainda, as porcentagens de ocorrência das formas variantes por ano de escolaridade, observa-se que no $5^{\circ}$ ano houve a menor ocorrência do apagamento do 'd' no grupo -ndo. Os resultados encontrados para o apagamento do /d/ no grupo -ndo mostram que os alunos, na leitura oral, usam pouco a forma com apagamento, o que confirma, em parte, os achados de Martins (2004) com análise de dados de língua falada, uma vez que, para a autora, a regra de apagamento diminui à medida que a escolaridade avança. Nos dados aqui analisados não há essa relação inversamente proporcional, pois a maior ocorrência da forma com apagamento se verifica no $4^{\circ}$ ano.

Realizada essa análise geral dos resultados, será feito um detalhamento a seguir.

\section{Monotongação}

O sistema ortográfico do português do Brasil, representado nas gramáticas normativas e nos manuais de ensino da língua, reconhece como ditongo o encontro de uma vogal e uma semivogal na mesma sílaba. Funcionam como semivogais o i e o u, que são representados fonologicamente por /y/ e /w/. No entanto, nem todo vocábulo que comporta um ditongo na escrita tem o mesmo comportamento na fala espontânea. Assim, em vocábulos como faixa, feira, vários, que o sistema ortográfico considera portadores de ditongo, na língua falada, esses mesmos vocábulos podem comportar uma vogal simples, o monotongo, <faxa>, $<$ fera $>$, <varos $>$; já outros, como leite, jeito, pai, por exemplo, não permitem o 
apagamento da semivogal. Contudo, essa particularidade do ditongo quase não é discutida nas gramáticas normativas.

Cunha e Cintra (1985, p.49, grifo do autor), em sua Nova gramática do português contemporâneo, fazem referência ao apagamento da semivogal, na seguinte observação:

Nem na pronúncia normal de Portugal nem na do Brasil se conserva o antigo ditongo [ow], [...]. Na pronúncia normal reduziu-se a [o], desaparecendo assim a distinção de forma como poupa / popa, bouba / boba.

Câmara Junior (1986, p.170, grifo do autor) define a monotongação enfatizando seu caráter fonético:

Mudança fonética que consiste na passagem de um ditongo a uma vogal simples [...]. Para pôr em relevo o fenômeno da monotongação chama-se, muitas vezes, MONOTONGO à vogal simples resultante, principalmente quando a grafia continua a indicar o ditongo e ele ainda se realiza numa linguagem mais cuidadosa. Entre nós há, nesse sentido o monotongo ou /ô/, em qualquer caso, e ai /a/, ei /ê/ diante de uma consoante chiante; exs.: (p)ouca, como (b)oca, (c)caixa, como acha, (d)deixa), como fecha.

O processo de monotongação, aqui referido, é resultante, portanto, do apagamento das semivogais [y] e [w], o que ocasiona a redução do ditongo a vogal simples, o monotongo. O autor ressalta a ocorrência da monotongação do ditongo /ow/ em qualquer contexto e de /ay/ e /ey/ diante de chiante. A essas ocorrências foi acrescentada a deste último, diante de outra consoante como em dinhero para dinheiro. Como, também, a ocorrência da monotongação com outros ditongos: / y/ munto para muito, /yo/ varos para vários. Essa tendência a reduzir os ditongos é atestada no português ao longo de sua história, conforme mostram os manuais e gramáticas históricas (CÂMARA JUNIOR, 1976; COUTINHO, 1978).

No português do Brasil a monotongação tem sido abordada por vários estudiosos: Bisol (1989, 1994), Paiva (1996a, 1996b), Silva (1997, 2004), Mollica (1998), tanto na linguagem oral quanto na escrita. No que se refere à linguagem falada, o uso variável da forma monotongada é observada na fala de diversas comunidades brasileiras, fato verificado através dos vários estudos de cunho variacionista em diversas regiões do País (PAIVA, 1996a, 1996b; SILVA, 1997, 2004). Dentre esses interessa de forma particular o trabalho de Silva $(1997,2004)$, uma vez que a comunidade analisada pela autora se situa no mesmo Estado do presente estudo. Portanto, os falantes das duas comunidades analisadas possuem características linguísticas muito próximas, o que favorece a comparação entre os resultados obtidos na análise da linguagem falada de forma espontânea (SILVA, 1997, 2004) e neste estudo, com a leitura oral. 
O trabalho de Mollica (1998), assim como a presente pesquisa, está voltado para as questões de variação no contexto de sala de aula, isto é, para o processo de ensino e aprendizagem da língua. Em seu estudo, a autora analisou o processo de monotongação relacionado à aquisição da língua escrita, buscando contribuir para uma melhor compreensão da influência da linguagem oral sobre a escrita.

A autora dividiu os alunos pesquisados em dois grupos: um que recebeu instruções sobre as regras de monotongação na fala e outro que não as recebeu. Com base nos resultados, ela apresenta alguns pontos conclusivos, entre os quais destacam-se: (1) os grupos que receberam instrução sobre a possível interferência da fala na escrita apresentaram um índice menor de monotongação, "[...] o que leva a supor que a consciência explícita por parte do falante acerca da relação fala/escrita concorre para melhorar o desempenho no processo de alfabetização." (MOLLICA, 1998, p.79); (2) turmas de alfabetização e de $1^{a}$ série ainda não são sensíveis a uma orientação explícita sobre a influência da fala na escrita, uma vez que nessas turmas " [...] o alfabetizando está assimilando ainda a relação fonema/ grafema, processo suficientemente complexo para introduzir-se mais informação sobre fala/escrita." (MOLLICA, 1998, p.79). (3) A 2 2a série é considerada o momento adequado para se introduzir essa orientação sobre a relação fala/escrita, pois é a partir dessa série que os alunos começam a entender as diferenças entre uma e outra forma de linguagem. (4) Observando os ditongos /ey/ e /ow/ constatou-se que a correção para o ditongo /ow/ é mais lenta que a do ditongo /ey/, fato que pode ser explicado em virtude de "[...] quanto mais afetada na fala a mudança, maior resistência à instrução, aplicada como estratégia pedagógica em sala de aula no processo de letramento." (MOLLICA, 1998, p.80).

Estudos com dados de língua falada concluem que o apagamento da semivogal do ditongo /ow/ configura uma mudança totalmente implementada no sistema (PAIVA, 1996a), ou um estado de mudança praticamente consumado (SILVA, 2004).

Nos dados analisados para este artigo, a supressão da semivogal apresenta comportamento diferente dos apresentados por Paiva (1996a, 1996b), Mollica (1998) e Silva (2004) em relação à escolaridade. Nos resultados apresentados por Paiva (1996b), com relação às crianças, a supressão da semivogal /y/ independe do grau de escolarização. Assim, as crianças do primário (atualmente $1^{a}$ fase do fundamental - $1^{\circ}$ ao $5^{\circ}$ ano) e as do ginásio ( $2^{\mathrm{a}}$ fase do fundamental $-6^{\circ}$ ao $9^{\circ}$ ano) apresentaram probabilidades semelhantes na aplicação da regra de supressão: .51 e .50, respectivamente. Os resultados obtidos por Mollica (1998) levam-na a concluir que, com a evolução do ano de escolaridade, o apagamento da semivogal tende a reduzir-se mais rapidamente quando há orientação específica sobre a relação fala/escrita. Em sua análise, Silva (2004) observa que, com o ditongo /ow/, a escolarização não interfere no apagamento da semivogal; já com os ditongos /ey/ e /ay/, os falantes com mais anos de escolaridade são menos favoráveis ao apagamento da semivogal. 
Nesta pesquisa com dados de leitura oral, os resultados evidenciam uma relação oposta entre ano de escolaridade e uso do ditongo, ou seja, na medida em que avança na escolaridade há diminuição do uso da forma com ditongo, conforme pode-se observar no Gráfico 1.

\section{Gráfico 1 - Porcentagem de monotongação}

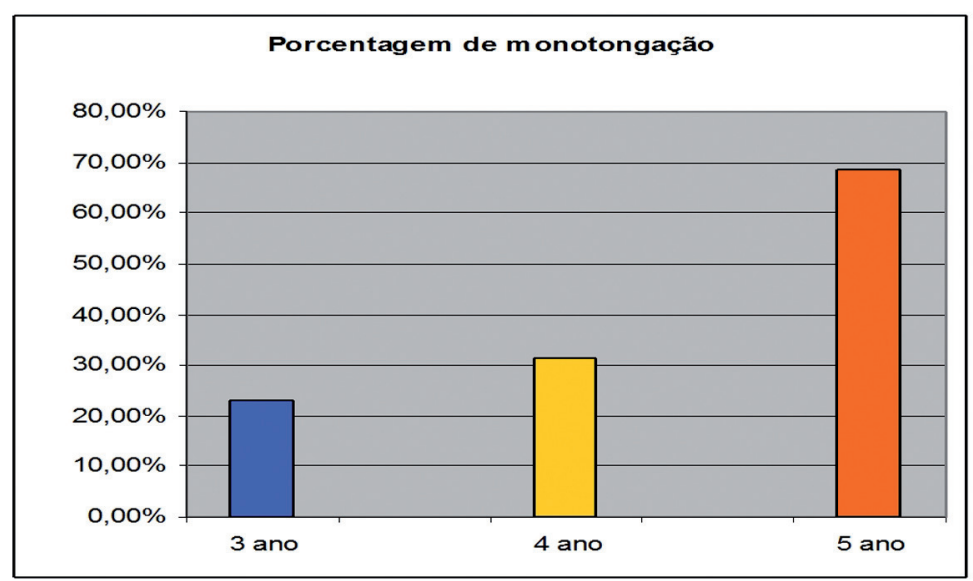

Fonte: Elaboração própria.

Como pode ser observado no Gráfico 1, a manutenção do ditongo é inversamente proporcional ao avanço da escolaridade, enquanto os alunos dos $3^{\circ}$ e $4^{\circ}$ anos apagam em $(21,08 \%)$ e $(31,54 \%)$ respectivamente, o $5^{\circ}$ ano aplicou a monotongação em $68,46 \%$ das ocorrências, o que mostra uma diferença acentuada entre o $3^{\circ}$ e o $5^{\circ}$ ano. Para melhor compreensão dos resultados obtidos na análise quantitativa, procedeu-se a uma análise qualitativa da leitura dos alunos, o que revelou aspectos importantes sobre o uso da monotongação. Depreende-se que a elevada porcentagem da forma monotongada para os alunos do $5^{\circ}$ ano pode estar relacionada à aplicação, quase que categórica, da regra de apagamento da semivogal do ditongo / ow/, o que pode ser justificado pelo fato de, na linguagem falada, a forma monotongada desse ditongo se encontrar em estado de mudança praticamente implementada no sistema (PAIVA, 1996a; SILVA, 2004). Embora o contexto de uso exigisse uma monitoração maior da linguagem, os alunos do $5^{\circ}$ ano, por terem maior proficiência na leitura, leram de forma mais espontânea que os do $3^{\circ}$ e $4^{\circ}$ anos, o que contribuiu para o uso da linguagem mais próxima da fala. A justificativa para a menor ocorrência da forma monotongada no $3^{\circ}$ ano pode ser a mesma aplicada para o apagamento do rótico, isto é, o uso intenso da mediação fonológica no processo de leitura, favorecendo a pronúncia de todos os fonemas da palavra. 
O que também se observa é que enquanto o apagamento da semivogal do ditongo /ow/ é muito elevado, a manutenção dos ditongos /ey/ de jeito e /yo/ de vários é quase categórica. Com dados de língua falada, Silva (2004) constatou que o ditongo /ey/ seguido da oclusiva /t/ conserva a semivogal quase que de forma categórica. Desse modo, pode-se concluir que, com os alunos pesquisados, principalmente os do $5^{\circ}$ ano, há tendência à aplicação, na leitura, das mesmas regras de monotongação aplicadas à fala espontânea.

Com base na análise das ocorrências dos dois tipos de ditongo na leitura dos alunos, depreende-se que parece haver diferença no grau de estigmatização dos ditongos crescentes e decrescentes, em que os primeiros tendem a ser mais sensíveis à estigmatização, o que os caracteriza como pertencentes a uma fala menos cuidada, própria de uma classe sociocultural menos prestigiada; já os ditongos decrescentes, em particular o ditongo /ow/, não sofrem estigmatização sendo, portanto, característicos de qualquer classe social. Desta forma, a monotongação dos ditongos crescentes é mais passível de correção pelo professor, que a dos ditongos decrescentes, fato que pode ter colaborado, na leitura dos alunos, para a restrição de uso da monotongação para os primeiros e sua ampliação para os últimos.

\section{Ditongação}

A ditongação é um processo que ocorre em direção contrária à monotongação. Enquanto nesta existe a supressão da semivogal, na ditongação há a inserção. Assim, a ditongação pode ser entendida como um fenômeno essencialmente fonético, cuja realização acontece na fala; estando, portanto, sujeita a variações sociolinguísticas (linguísticas e extralinguísticas), a exemplo do tamanho do vocábulo, do contexto fonético, da escolarização, do nível de registro de fala etc.

Coutinho (1978, p.110) aponta, na história do português, algumas causas que contribuíram para a manutenção e aparição de ditongos: a síncope ou queda de fonema medial: malu > mau, lege > lei, palu > pau; a vocalização ou transformação de consoantes em vogal, em certos grupos consonantais: alt(e)ru > *autro > outro; factu > *faito > feito; regnu > reino; a metátese ou transposição de fonemas: primariu > * primairo > primeiro, librariu > *livrairo > livreiro; a epêntese de vogal para desfazer hiatos: creo $(<$ credo) > creio, tea $(<$ tela $)>$ teia. No português do Brasil, o autor chama a atenção para a ditongação na fala, com vogal em posição tônica final de palavras seguida de /s/ ou /z/: gás gais, rapaz rapais.

Câmara Junior (1986, p.100) define a ditongação como "[...] mudança fonética que consiste na formação de um ditongo sistemático a partir de uma vogal simples." Ao tratar do fenômeno na língua portuguesa moderna, o autor afirma que a ditongação se deu nos seguintes casos: 
1) Vogal tônica em hiato, quando a) média anterior, com o desenvolvimento de um ditongo /éy/ ou /êy/, indicado na grafia moderna - ideia, veia; b) média posterior fechada com o desenvolvimento de um ditongo /ôw/, não indicado na grafia e inexistente nas zonas dialetais em que houve a monotongação do ditongo /ôw/ - boa bôwa.

2) Dialetalmente, para vogal tônica final travada por /s/ pós-vocálico, com o desenvolvimento dos ditongos de pospositiva /y/ - pás, és, fez, sós, flux, pronunciadas pays, feys, sóys, fluys. Dá-se, então, a neutralização da oposição entre ditongo e vogal simples, desaparecendo a distinção em casos como: pás e pais (CÂMARA JUNIOR,1986, p.101).

Em estudos mais recentes sobre o português do Brasil, Bisol (1989, 1994), em uma análise fonológica do ditongo, afirma que em muitas variedades do português há tendência para o surgimento de um glide em palavras como três, mas, rapaz, e que isto acontece somente em sílaba acentuada e em posição final de palavra. A autora classifica os ditongos em verdadeiros e falsos; os primeiros estão representados por duas vogais no nível subjacente, os últimos possuem um glide epentético, sem representação na estrutura subjacente, formado na estrutura de superfície por expansão de um traço vocálico da consoante vizinha. Seguindo essa proposta, a ditongação presente na fala, em contextos que na escrita se realiza com vogal simples - faxina $\sim$ fayxina, faz $\sim$ fays, se insere na classificação dos falsos ditongos.

Como pode ser observado nos estudos referidos, a ditongação é um fenômeno antigo na história do português e ainda recorrente, conforme atestam, também, pesquisas com dados de língua falada no português brasileiro (LEIRIA, 1995; AQUINO, 1998, 2004; LEITE; CALLOU; MORAES, 2003), inclusive com a inserção do glide em outros contextos - nayscimento nascimento - além da posição final da palavra.

O uso variável da ditongação em diversas comunidades brasileiras é atestado em estudos de base variacionista com dados de várias regiões do País. Leiria (1995), analisando dados de fala da região sul (VARSUL) e considerando apenas sílabas tônicas finais, destacou alguns fatores linguísticos relevantes para a formação do ditongo, como sândi externo, a qualidade da vogal e o ponto de articulação da consoante. Aquino (1998, 2004), investigando dados do Nordeste (VALPB), constatou que os fatores linguísticos exercem maior influência no processo de ditongação que os fatores sociais; entre os fatores linguísticos favorecedores, destacam-se: a tonicidade da sílaba, a qualidade da vogal e o status morfêmico da sibilante; em relação aos fatores sociais, os dados revelaram que os falantes mais escolarizados inibem a aplicação da forma ditongada.

Leite, Callou e Moraes (2003), analisando dados do Rio de Janeiro (NURC), observaram que a inserção do glide pode dar-se com qualquer uma das realizações 
do arquifonema /S/, com preferência para a palatal e para vocábulos monossilábicos - paz pays, faz fays. Os autores constataram, também, a ocorrência do fenômeno na posição medial de palavra, embora restrita a poucos vocábulos.

Dentre os estudos referidos, interessa, de forma particular, o trabalho de Aquino $(1998,2004)$, uma vez que a comunidade analisada pela autora se situa no mesmo Estado do presente estudo, o que favorece, portanto, a comparação entre os resultados obtidos nas duas análises.

Comparando os dados de leitura com os de fala na análise de Aquino (1998, 2004), constata-se que a ditongação apresenta comportamento divergente nas duas pesquisas em relação à influência da escolaridade. Os resultados obtidos na análise de fala espontânea mostram que os falantes mais escolarizados desfavorecem a aplicação da regra de ditongação; já nos resultados com os dados de leitura, são os alunos mais escolarizados aqueles que mais usam a forma ditongada, conforme o Gráfico 2.

\section{Gráfico 2 - Porcentagem de ditongação}

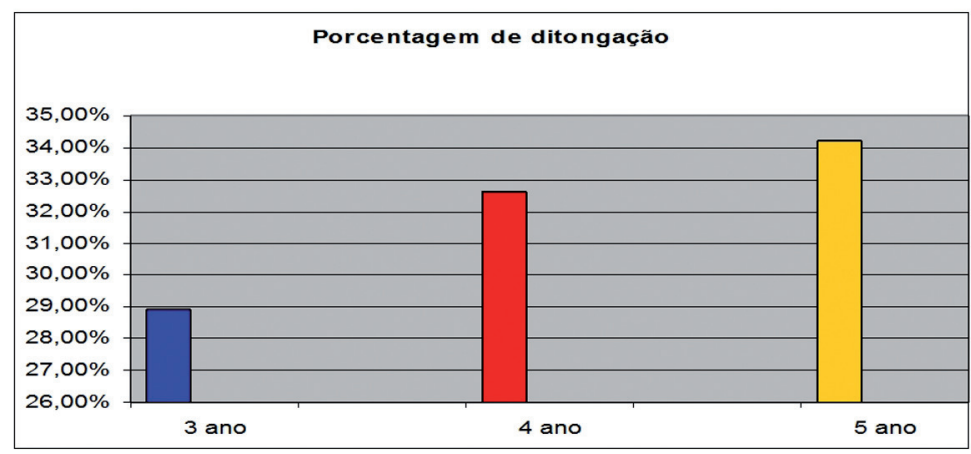

Fonte: Elaboração própria.

Os valores obtidos, conforme o Gráfico 2, mostram que o processo de ditongação se comporta de forma inversamente proporcional ao avanço da escolaridade, embora não haja uma diferença tão acentuada entre os três anos: $3^{\circ}$ ano $(28,89 \%)$, $4^{\circ}$ ano $(32,63 \%)$ e $5^{\circ}$ ano (34,21\%). No entanto, considerando-se resultados obtidos por Aquino $(1998,2004)$ e a tendência nos estudos de língua falada em associar a predominância de formas padrão a falantes mais escolarizados, era de se esperar que os alunos do $5^{\circ}$ ano usassem menos ditongação que os do $3^{\circ}$ e $4^{\circ}$ anos.

De posse dos valores estatísticos por cada ano de escolaridade, é necessário voltar aos dados com o objetivo de observar quais aspectos linguísticos das palavras analisadas favorecem o uso da ditongação. Constata-se, então, que as palavras monossilábicas (vez, fez, voz) foram lidas com ditongo (/veys/, feys/, /voys/) por todos os alunos, independentemente do ano de escolaridade. 
Possivelmente isto tenha contribuído para a pequena diferença percentual entre os anos. Essa constatação do amplo uso do ditongo nas palavras monossilábicas corrobora resultados obtidos em pesquisas sobre língua falada. Aquino $(1998,2004)$ constata que, com os monossílabos de uso tônico, a aplicação da ditongação é de (97\%). Leite, Callou e Moraes (2003) encontram resultados que vão nesta mesma direção, uma vez que os resultados apontam a preferência da inserção do glide em vocábulos monossilábicos.

De certo modo, alguns resultados dos dados de fala foram confirmados na análise dos dados de leitura, conforme pode ser visualizado na Tabela 2, em que se apresenta a porcentagem de ocorrência da ditongação com dados de língua falada e a ocorrência na leitura.

Tabela 2 - Comparação entre dados de fala e dados de leitura

\begin{tabular}{lll}
\hline \multicolumn{1}{c}{ Fatores } & $\begin{array}{l}\text { \% de ocorrência } \\
\text { na fala (AQUINO, } \\
\text { 1998) }\end{array}$ & Ocorrência na leitura \\
\hline $\begin{array}{l}\text { Monossílabo de uso tônico } \\
\text { (três) }\end{array}$ & $97 \%$ & $\begin{array}{l}\text { Uso ditongado em todas as } \\
\text { ocorrências }(100 \%)\end{array}$ \\
\hline $\begin{array}{l}\text { Final postônica de palavra } \\
\text { (aquelas) }\end{array}$ & $3 \%$ & $\begin{array}{l}\text { As duas palavras que } \\
\text { apresentaram esse contexto } \\
\text { foram lidas com a vogal } \\
\text { simples }(0 \%)\end{array}$ \\
\hline $\begin{array}{l}\text { Inicial pretônica de palavra } \\
\text { (nascer) }\end{array}$ & $6 \%$ & $\begin{array}{l}\text { Houve 16 usos de } \\
\text { ditongação com a palavra } \\
\text { nascido }\end{array}$ \\
\hline $\begin{array}{l}\text { Inicial tônica de palavra } \\
\text { (festa) }\end{array}$ & $0 \%$ & $\begin{array}{l}\text { Houve } 4 \text { usos da forma } \\
\text { ditongada com a palavra } \\
\text { festa }\end{array}$ \\
\hline
\end{tabular}

Fonte: Elaboração própria.

Um fato que chamou a atenção foi o amplo uso do ditongo na palavra nascido. Dos 30 (trinta) alunos que leram o texto, 16 (dezesseis) usaram a forma ditongada. Pode-se ver nesse fato a presença da interferência da norma da comunidade na fala dos alunos e sua transposição para a leitura ou, mais especificamente, a rede social do indivíduo (pessoas com quem ele interage nos diversos domínios sociais, determinando as características de seu repertório linguístico (BORTONI-RICARDO, 2004). Tal fato leva a inferir, portanto, que, na comunidade de fala desses alunos, o uso vigente da palavra nascido é a forma ditongada nayscido. 
Com base na análise quantitativa e qualitativa e, também, nos resultados encontrados nas referidas pesquisas com língua falada, pode-se afirmar que a ditongação diante de /S/ em monossílabos tônicos e na posição tônica final já tem seu uso bem consolidado no português brasileiro. Constata-se também que, por se tratar de uma forma que não sofre estigma social, passa despercebida pelo crivo corretivo da escola, o que a faz ser usada tanto em situações informais como em contextos sociais em que há maior monitoramento da linguagem, como no contexto de leitura.

\section{Apagamento da oclusiva dental 'd' no grupo -ndo}

O fenômeno em análise consiste no resultado da assimilação do fonema /d/ pelo fonema $/ \mathrm{n} /$ em contextos como: imaginando $\sim$ imaginano, falando $\sim$ falano, quando quano, ou seja, há uma assimilação do /d/ pelo /n/ para, em seguida, haver o apagamento do fonema (-nd- > -nn- >-n-). Este processo de apagamento da oclusiva /d/ não é exclusividade do português brasileiro; ele está presente também em outras línguas (MARTINS, 2004).

Na literatura pertinente, pode-se constatar a produtividade do fenômeno na língua falada em diversas regiões do País. No Atlas Linguístico da Paraíba (ARAGÃO, 1984), há registros de apagamento do 'd' no grupo -ndo em várias localidades como Mamanguape, Campina Grande, Guarabira. Martins (2004), utilizando dados do VALPB, constatou que existe um maior apagamento da oclusiva dental 'd' (58\%) do que de sua preservação (42\%) na fala dos pessoenses.

Com o objetivo de observar a influência da fala na escrita, Mollica (1998) analisou a assimilação da dental em -ndo na escrita de alunos da $5^{a}$ à $8^{a}$ série. Os resultados mostraram que fatores linguísticos e sociais, como a extensão do item lexical, escolaridade, sexo relevantes para a assimilação do fenômeno na fala foram, também, relevantes na escrita. A autora destaca que os ambientes favorecedores da assimilação da dental são os de maior dificuldade para a aprendizagem da escrita.

Neste estudo, o apagamento do 'd' no grupo -ndo foi o que apresentou a menor frequência (4,81\%). Analisando a frequência do fenômeno por ano de escolaridade, verifica-se o menor índice de ocorrência no $5^{\circ}$ ano, conforme pode ser visualizado no Gráfico 3. 


\section{Gráfico 3 - Porcentagem de apagamento da oclusiva dental /d/ no grupo -ndo}

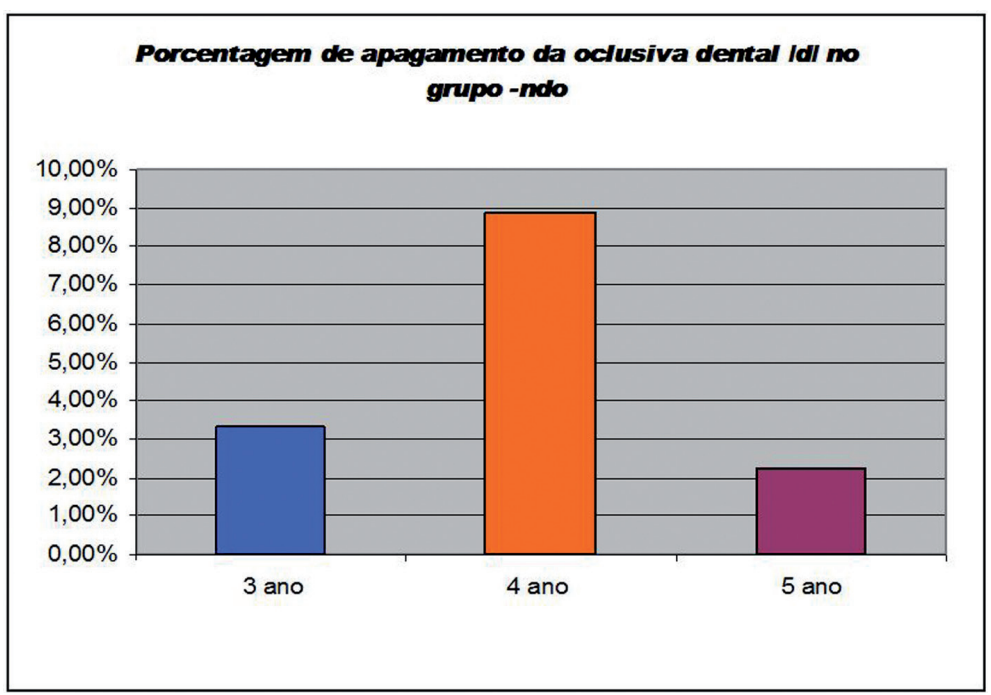

Fonte: Elaboração própria.

Os resultados mostram porcentagem maior de apagamento da oclusiva no $4^{\circ}$ ano, o que foi surpreendente, pois se esperava um decréscimo de apagamento com o avanço da escolaridade, fato já constatado em pesquisa com língua falada (MARTINS, 2004).

Voltando aos dados, verifica-se que todas as ocorrências de apagamento do 'd', em todos os anos, aconteceram com a forma verbal no gerúndio, cujo resultado corrobora os achados de Martins (2004), com dados de língua falada, em que o índice mais alto de ocorrência se deu com o gerúndio (68\%), e também Mollica (1998), com dados de escrita, em que o maior índice de ocorrência se deu com o gerúndio, com destaque para o gerúndio fático. Embora não tenha sido objetivo deste trabalho controlar as variáveis condicionadoras do fenômeno em análise, os resultados dão indicativos de que o gerúndio é o contexto favorecedor da ocorrência do apagamento da dental em -ndo, também na leitura.

Com base nos resultados, percebe-se que o apagamento da oclusiva dental como fenômeno variável não se apresentou de forma produtiva na leitura dos alunos pesquisados, o que leva a concluir que este fenômeno não pode ser concebido como um problema para o desenvolvimento da leitura oral na primeira fase do ensino fundamental ( $3^{\circ}$ ao $5^{\circ}$ ano). 


\section{Considerações finais}

Os resultados apontaram o caráter variável, na leitura, de alguns fenômenos linguísticos característicos da oralidade. Comparando os dados de leitura com os de fala espontânea, constata-se que alguns resultados corroboram os encontrados em estudos sobre a língua falada na comunidade pessoense (SILVA, 1997, 2004; AQUINO, 1998, 2004; MARTINS, 2004).

Nos fenômenos variáveis analisados, os que apresentaram maior índice de ocorrência são, em geral, formas não estigmatizadas, já bastante consolidadas na fala espontânea. No geral, a realização dessas formas variáveis na leitura dos alunos não traz influência negativa no desempenho da leitura, pois não comprometem sua fluência nem a compreensão do que é lido. As formas estigmatizadas, como são mais propensas à correção pelo professor, ocorrem com menos frequência e tendem a declinar de uso com o avanço da escolaridade.

Os resultados deste estudo mostram uma realidade de sala de aula ainda pouco discutida no cenário acadêmico e educacional. O conhecimento, por parte do professor, das formas variantes na leitura dos alunos e sua interferência no processo de ensino/aprendizagem são muito importantes para o desenvolvimento da competência comunicativa do aluno no ambiente escolar e fora dele. Nesse sentido, os estudos sociolinguísticos de base variacionista têm contribuído de forma significativa ao trazer à tona variedades linguísticas presentes em qualquer ambiente social, dentre eles, o escolar. O trabalho de sala de aula que leva em consideração esses aspectos possibilita, ao aluno, a compreensão das variadas formas de uso da linguagem apropriadas aos diversos contextos sociais.

HORA, D.; AQUINO, M. F. From speech to reading: variation analysis. Alfa, São Paulo, v.56, n.3, p.1089-1105, 2012.

- ABSTRACT: Variation studies in Brazil have focused mostly on the phonological and syntactic linguistic levels. The various projects which are based on data collected in different communities (VARSUL, PEUL, IBORUNA, VALPB etc.) seek to address their findings by using all the theoretical apparatus that Variation Sociolinguistics has made available. Based on the results of the implementation of Projeto Variação Linguística no Estado da Paraíba (Linguistic Variation in the State of Paraiba Project) - VALPB (HORA, 1993), which corpus is stratified by gender, age and education level, and attempting to cast an eye on a new corpus, this paper considers the linguistic variation in oral reading done by students of the first phase of elementary school. The analyzed data indicate a strong influence of the dialectal variant of the student in oral reading. Of the various processes involved in the original project, three were selected, namely: monophthongization, diphthongization and the deletion of ' $d$ ' in the group -ndo. This relation between what the student speaks and what he/she reads motivates the search for analysis proposals that go beyond what the school recommends.

- KEYWORDS: Sociolinguistics. Variation. Reading and teaching. 


\section{REFERÊNCIAS}

AQUINO, M. F. S. Uso variável do ditongo em contexto de sibilante. In: HORA, D. (Org.). Estudos sociolinguísticos: perfil de uma comunidade. Santa Maria: Pallotti, 2004. p.45-54.

A ditongação na comunidade de João Pessoa: uma análise variacionista. 1988. 84f. Dissertação (Mestrado em Letras)-Universidade Federal da Paraíba, Centro de Ciências Humanas, Letras e Artes, João Pessoa, 1998.

ARAGÃO, M. S. S. Atlas linguístico da Paraíba: análise das formas e estruturas linguísticas encontradas. Brasília: Ed. da UFPB, 1984.

BISOL, L. Ditongos derivados. DELTA, São Paulo, v.10, n.esp., p.123-140, 1994.

. O ditongo na perspectiva da fonologia atual. DELTA, São Paulo, v.5, n.2, p.185-224, 1989.

BORTONI-RICARDO, S. M. Nós cheguemu na escola, e agora? sociolinguística e educação. São Paulo: Parábola, 2005.

. Educação em língua materna: a sociolinguística na sala de aula. São Paulo: Parábola, 2004.

CÂMARA JUNIOR, J. M. Dicionário de linguística e gramática: referente à língua portuguesa. 13.ed. Petrópolis: Vozes, 1986.

História e estrutura da língua portuguesa. Rio de Janeiro: Padrão, 1976.

COUTINHO, I. L. Pontos de gramática histórica. 7.ed. Rio de Janeiro: Ao Livro Técnico, 1978.

CUNHA, C.; CINTRA, L. F. L. Nova gramática do português contemporâneo. 2.ed. Rio de Janeiro: Nova Fronteira, 1985.

HORA, D. Projeto variação linguística no Estado da Paraíba. 1993.

LABOV,W.; BAKER, B. What is a reading error? University of Pennsylvania, 22 sep. 2003. Disponível em:<http://www.ling.upenn.edu/ wlabov/Papers/WRE.html>. Acesso em: 13 out. 2006.

. Testing the effectiveness of an individualized reading program for AfricanAmerican, Euro-American and Latino Inner city children. Pennsylvania:University of Pennsylvania, 2001. Disponível em: <http://www.ling.upenn.edu/ wlabov/ UMRP/UMRP.html>. Acesso em: 13 out. 2006.

LEIRIA. L. L. A ditongação variável em sílabas tônicas finais travadas por /s/. 1995. 74f. Dissertação (Mestrado em Letras) - Pontifícia Universidade Católica do Rio Grande do Sul, Porto Alegre, 1995. 
LEITE, Y.; CALLOU, D.; MORAES, J. Processos em curso no português do Brasil: a ditongação. In: HORA, D.; COLLISCHONN, G. (Org.). Teoria linguística: fonologia e outros temas. João Pessoa: Universitária, 2003. p.232-250.

MARTINS, I. F. M. Apagamento da oclusiva dental/d/: perspectivas variacionistas e fonológicas. In: HORA, D. (Org.). Estudos sociolinguísticos: perfil de uma comunidade. Santa Maria: Pallotti, 2004. p.55-82.

MOLLICA, M. C. Da linguagem coloquial à escrita padrão. Rio de Janeiro: 7Letras, 2003.

. Influência da fala na alfabetização. Rio de Janeiro:Tempo Brasileiro, 1998.

PAIVA, M. C. A. Supressão das semivogais nos ditongos decrescentes. In: SILVA, G. M. O.; SCHERRE, M. M. P. (Org.). Padrões sociolinguísticos: análise de fenômenos variáveis do português falado na cidade do Rio de Janeiro. Rio de Janeiro:Tempo Brasileiro, 1996a. p.217-236.

Atuação das variáveis sociais na supressão da semivogal anterior nos ditongos decrescentes. In: SILVA, G. M. O.; SCHERRE, M. M. P. (Org.). Padrões sociolinguísticos: análise de fenômenos variáveis do português falado na cidade do Rio de Janeiro. Rio de Janeiro: Tempo Brasileiro, 1996b. p.325-333.

R DEVELOPMENT CORE TEAM. $R$ : a language and environment for statistical computing. Vienna, 2007. Disponível em: <http://www.R-project.org > . Acesso em: 24 abr. de 2010.

SILVA, F. S. O processo de monotongação em João Pessoa. In: HORA, D. (Org.). Estudos sociolinguísticos: perfil de uma comunidade. Santa Maria: Pallotti, 2004. p.29-43.

O processo de monotongação em João Pessoa. 1997. 120f. Dissertação (Mestrado em Letras) - Universidade Federal da Paraíba, João Pessoa, 1997.

Recebido em abril de 2012

Aprovado em junho de 2012 